\title{
Les càmeres digitals, la xarxa... i el darrer Nobel de física
}

\author{
Juan Campos \\ Grup d'Òptica, Departament de Física, Universitat Autònoma de Barcelona. \\ Juan.Campos@uab.cat
}

El darrer Nobel de física ha premiat els treball de tres científics que han obert el camí a les càmeres digitals i a la transmissió eficient de senyals digitals, la base de la xarxa.

Paraules clau: CCD, Ilum, digital, sensor, color, senyal digital, fibra òptica, refracció, atenuació

El darrer premi Nobel de Física ha estat adjudicat el 2009 a tres investigadors en el camp de les tecnologies de la informació (fig. 1) que han contribuït a posar les bases per a la nostra actual xarxa de comunicacions.

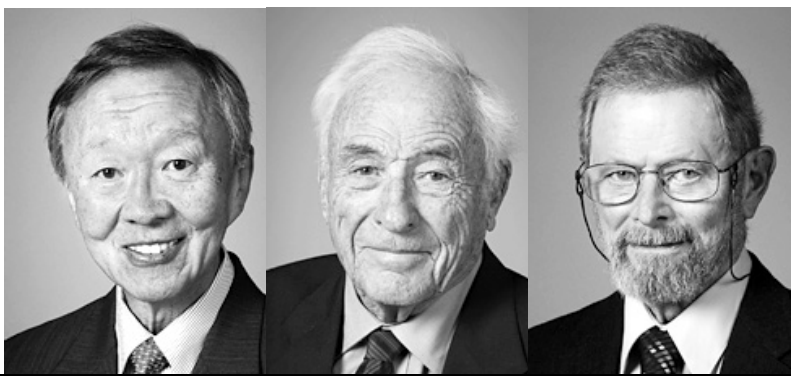

Figura 1. Charles K. Kao (esquerre) ve rebre la meitat del premi, mentre que Willard S. Boyle (centre) i George E. Smith (dreta) compartiren l'altra meitat. (nobelprize.org)

Kao va ser premiat per la seva contribució a la millora de la comunicació de dades per fibra òptica, mentre que Boyle i Smith ho foren per la invenció del sensor CCD (Charge-Coupled Device), basat en circuits semiconductors capaços de captar imatges; actualment és l'ull electrònic de les nostres càmeres digitals.

\section{De la cambra obscura al sensor CCD}

Les nostres càmeres digitals, tan còmodes i manejables, són el resultat actual d'un seguit de descobriments i invencions de moltes persones, realitzats al llarg de segles. En veurem alguns.

Leonardo da Vinci (1452-1519) realitzà la primera descripció completa i il-lustrada sobre el funcionament de la cambra obscura (fig. 2).

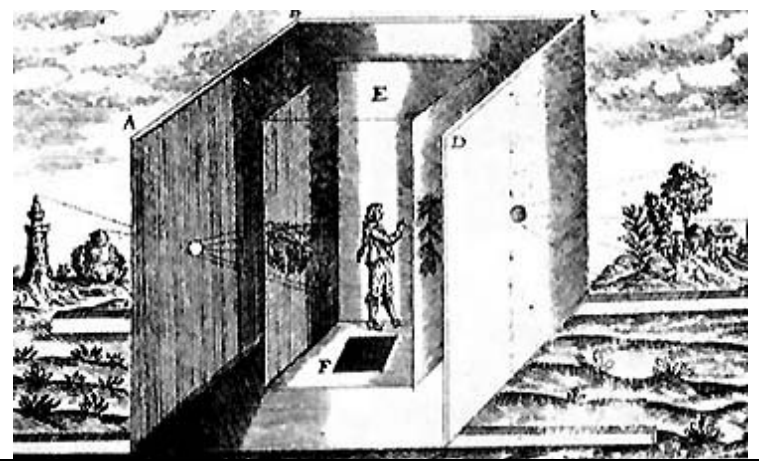

Figura 2. La cambra obscura, un valuós ajut per al dibuix.

Alguns artistes utilitzaven la cambra obscura (fig. 3) per dibuixar amb precisió les escenes.

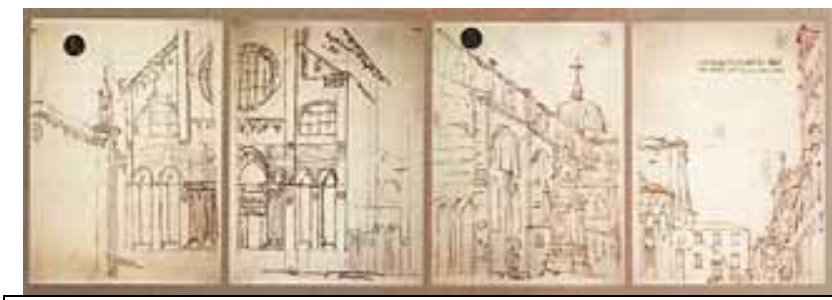

Figura 3. Apunts de Venècia fets per Canaletto utilitzant una cambra obscura. 
El francès Louis Daguerre va ser el primer, el 1839, d'enregistrar imatges per mitjans químics, creant el daguerreotip (fig. 4). Precisava una exposició de 60 a 90 segons. Fou superat el 1871 per l'aparició del gelatino-bromur, que permetia exposicions d'un quart de segon, apropant-se significativament al concepte d'instantània fotogràfica.
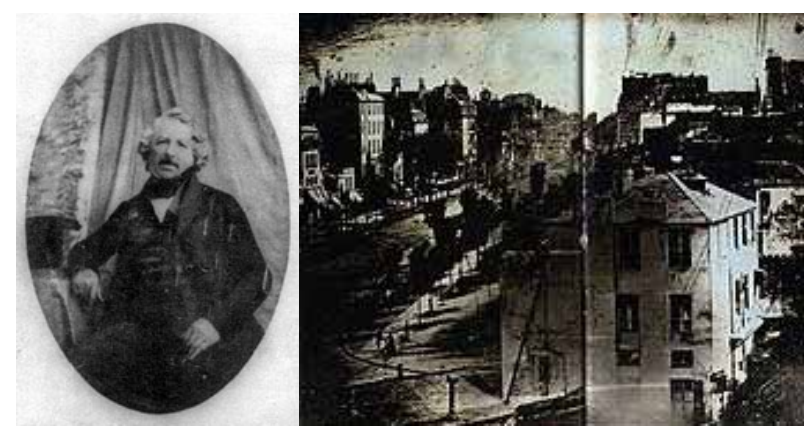

Figura 4. Imatge de Daguerre i un daguerreotip.

El 1888 el nord-americà George Eastman Ilença la càmera Kódak (fig. 5) amb gran èxit comercial. Amb ella s'introduiia al mercat el rodet de paper fotogràfic, provocant la substitució de les plaques de vidre utilitzades fins llavors. Posteriorment llançà també el rodet de cel·luloide amb una protecció (fig. 6) que permetia la seva extracció i col·locació fins i tot amb llum ambient.
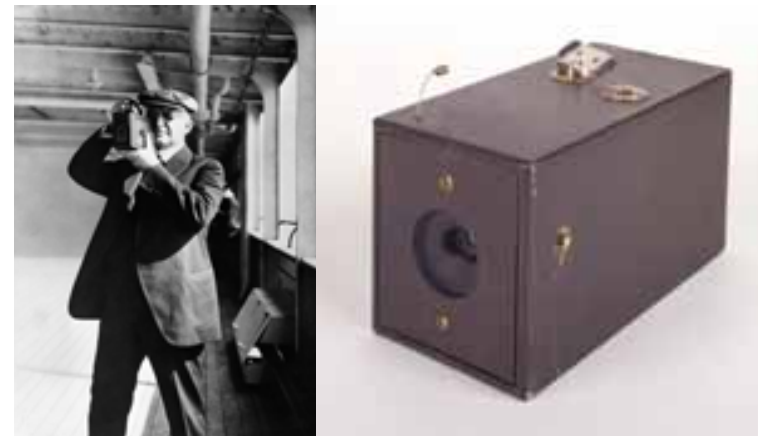

Figura 5. Eastman amb una de les seves càmeres Kódak, la primera de les quals es mostra a la dreta.

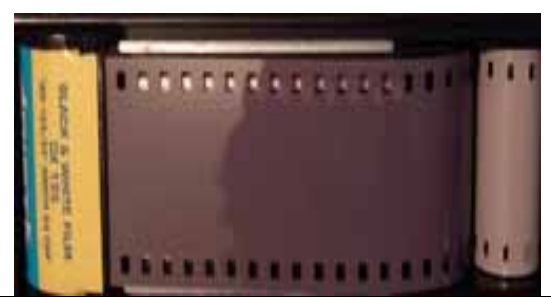

Figura 6. Rodet modern de pel-lícula fotogràfica.
El 1908 el francès Lippmann (fig. 7) va guanyar el Nobel de física pel seu mètode de reproducció de colors en fotografia. Havia nascut la fotografia en color.

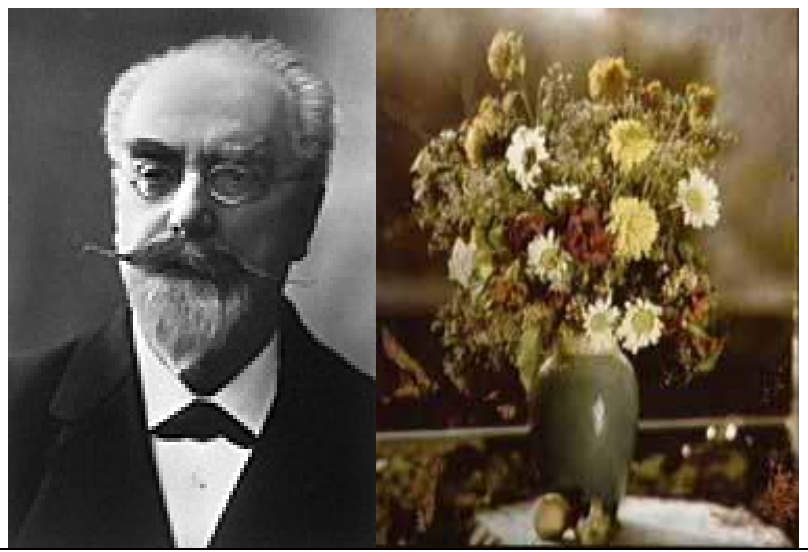

Figura 7. Gabriel Lippmann i una de les seves primeres fotografies en color.

El 1947 l'empresa Polaroid va sorprendre tothom amb la primera càmera (fig. 8) que proporcionava positius de les fotografies al moment (bé, per ser més precisos, després d'uns 60 segons).

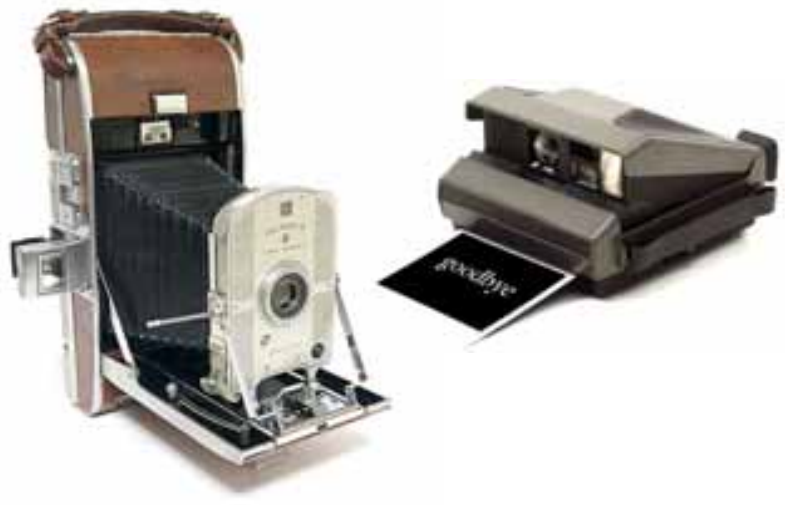

Figura 8. A l'esquerra, primera càmera Polaroid. Al seu costat, una de més moderna.

(collectiblend.com)

1947 va ser també l'any que l'hongarès Gabor descobrí l'holografia (fig. 9), que li valgué el Nobel de física el 1971.

La primera diapositiva moderna en color fou la Kodachrome, introduïda el 1935. Però la majoria de pel-lícules modernes en color (fig. 10) han utilitzat la tecnologia Agfacolor introduïda el 1936. 


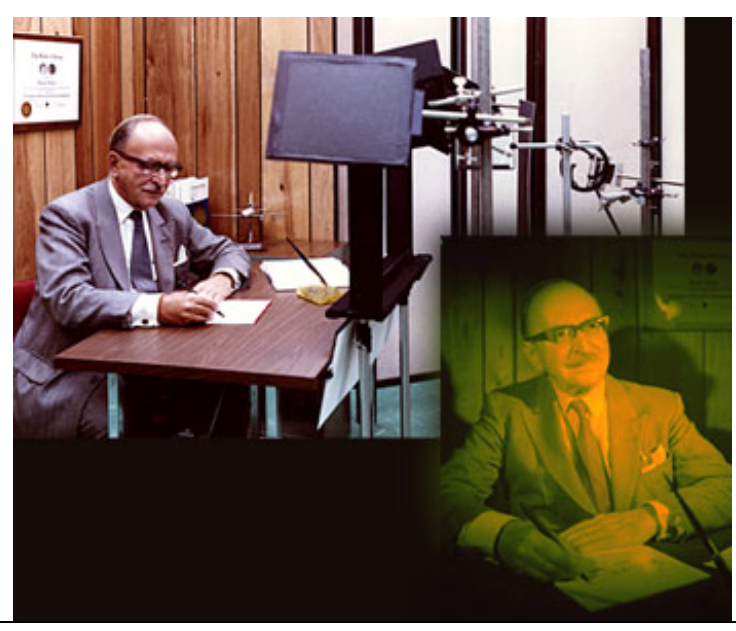

Figura 9. Dennis Gabor en una escena que s'està recollint en holografia. En el requadre, una imatge de l'holografia resultant. (nobelprize.org)

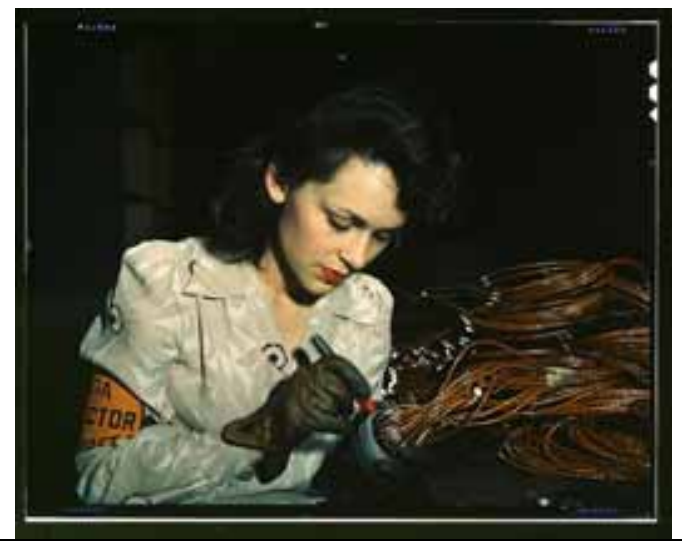

Figura 10. Diapositiva moderna.

\section{El sensor CCD}

Els passos següents vers la càmera digital parteixen de l'efecte fotoelèctric, descobert per Hertz el 1887 i explicat per Einstein el 1905, fet que li valgué el premi Nobel de física de 1921. Consisteix en arrencar un electró de la superfície d'un metall mitjançant llum d'una longitud d'ona adequada.

Perquè una càmera pugui substituir la retina humana per una altra de tecnològica, cal comprendre abans el funcionament de l'ull humà.

La nostra retina no és igualment sensible a totes les longituds d'ona visibles. Efectivament, tenim tres tipus de cèl-lules sensibles als colors, els cons, que responen principalment als colors blau, verd $\mathrm{i}$ roig (fig. 11).

A l'hora d'imitar-ho amb un dispositiu tecnològic, s'utilitzen tres filtres dels tres colors primaris per a mescles de llum additives: roig, verd i blau (fig. 12).

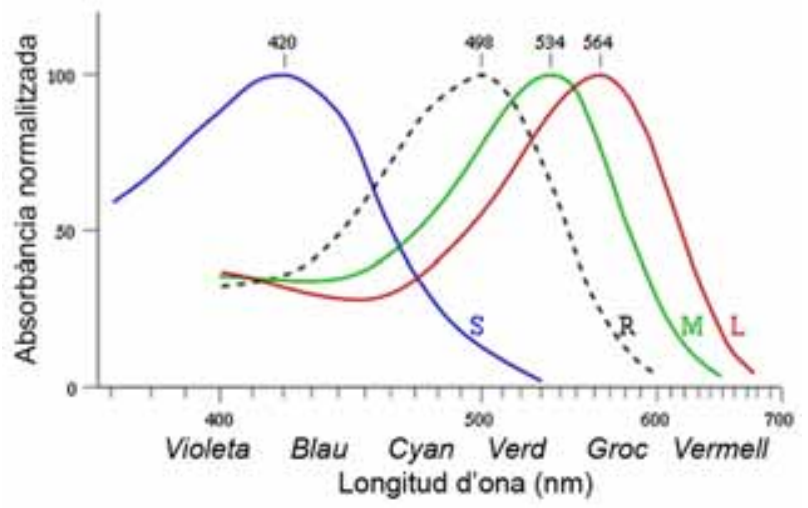

Figura 11. La gràfica mostra les respostes a les diferents longituds d'ona corresponents dels cons més sensibles al blau (S), al verd (M) $i$ al roig (L). També s'hi mostra la resposta dels bastons $(R)$.
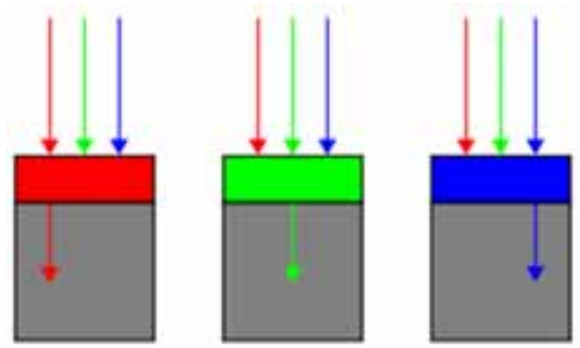

Llum incident
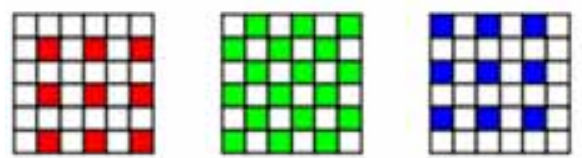

Patro

resultant

Figura 12. Cada sensor té al damunt un filtre de color. Per cadascun de blau o vermell n'hi ha dos de verds

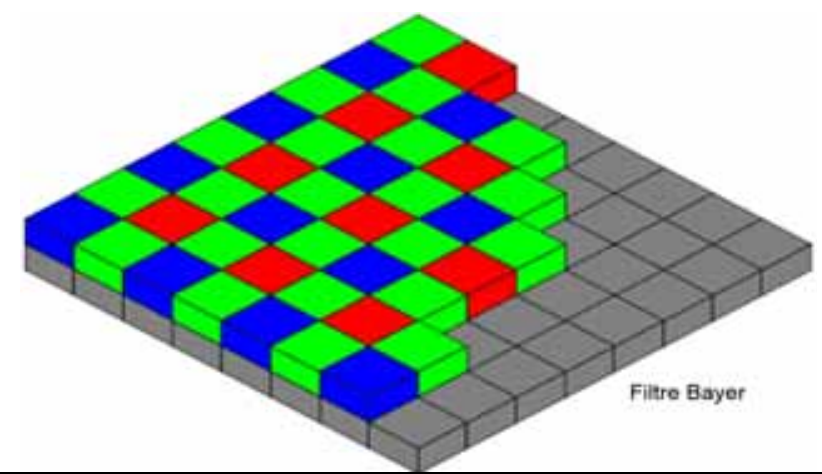

Figura 13. Matriu de sensors, mostrant l'anomenat filtre Bayer que potencia el color verd, imitant el que fa l'ull humà.

Però com que l'ull humà és més sensible a la llum verda que a les altres, a l'hora de formar la 
matriu dels sensors s'ha optat per incloure-hi el doble de sensors de color verd que no pas dels altres colors (fig. 13). (Per a satèl-lits artificials es construeixen matrius amb sensors de longituds d'ones visibles i no visibles, constituint els sensors anomenats hiperespectrals).

Quan cal molta resolució s'utilitza una altra estratègia: separar els colors mitjançant un dispositiu que utilitza la reflexió total, un divisor fabricat per Philips (fig. 14).

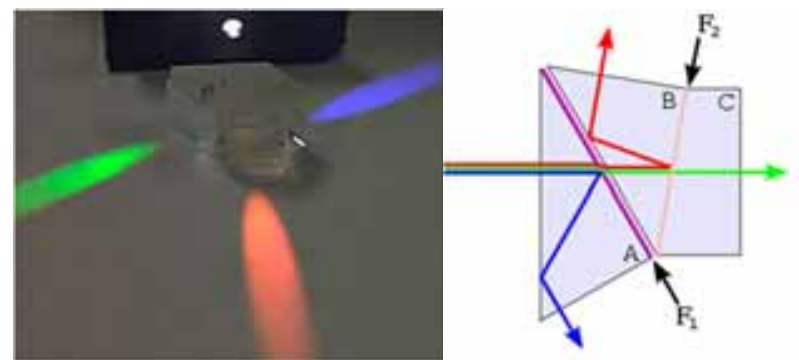

Figura 14. Imatge d'un divisor de la companyia Philips en funcionament. Hi entra llum blanca per la part posterior i el dispositiu la separa en els tres colors fonamentals. A la dreta, diagrama mostrant el funcionament d'un dispositiu semblant.

Com es pot veure al diagrama anterior, la llum blava sofreix una reflexió total quan arriba a l'aire (en el pla $F_{1}$ ). El mateix li succeeix a la llum vermella quan arriba a $F_{2}$, pla de separació de dos tipus diferents de cristalls, B i C.

El resultat que es busca és la conversió de la imatge en tres senyals de color diferents (fig. 15) que permetin reconstruir la imatge en color al final del procés.

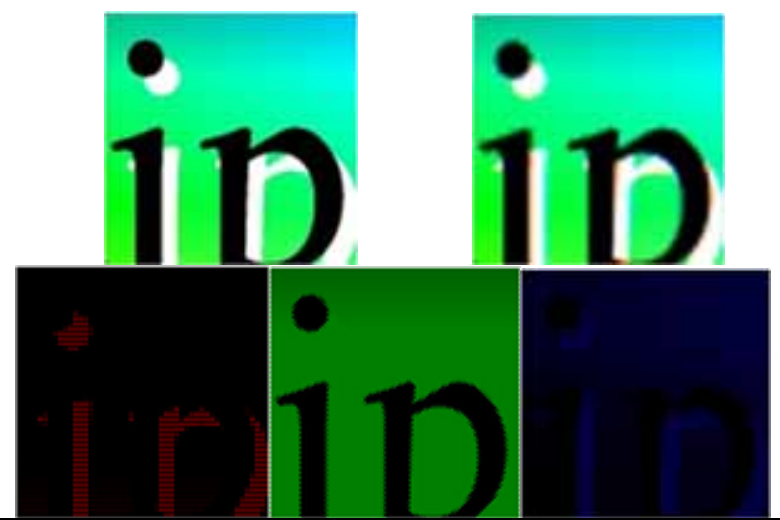

Figura 15. A dalt, imatge original (esquerra) i l'obtinguda digitalment (dreta). A la segona filera, imatges obtingudes amb cadascun dels filtres de color.
L'arribada de llum sobre un element del sensor proporciona energia als electrons del semiconductor, que acaben produint una acumulació de càrrega a la seva superfície (fig. 16).

Per llegir aquesta imatge s'utilitzen cíclicament sèries de valors de potencials (fig. 17) que van desplaçant les càrregues ordenadament d'una filera a la següent de la matriu de sensors (fig. 18). Finalment els valors dels voltatges són digitalitzats i convertits en informació amb la qual un altre dispositiu pot reconstruir la imatge original (fig. 19).

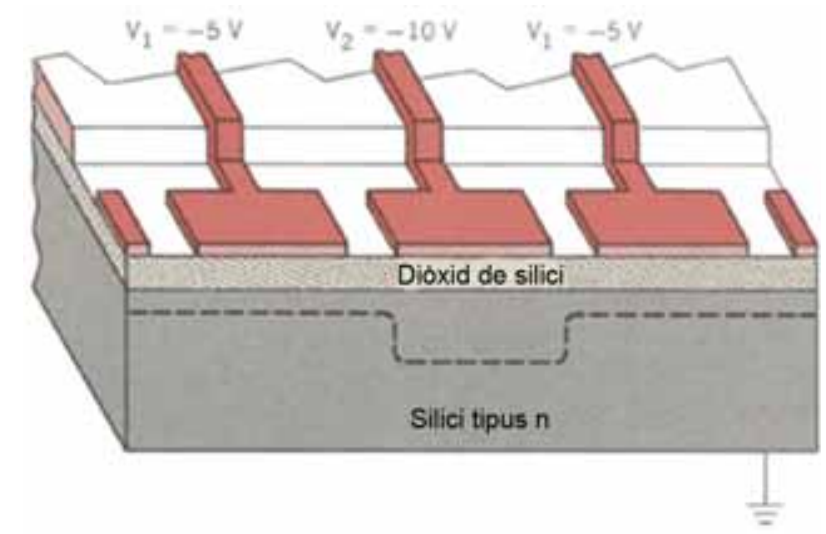

Figura 16. Diagrama d'un dispositiu de càrrega acoblada. La línia discontínua mostra tant el límit de la regió on s'acumula la càrrega com la variació del potencial elèctric. Els valors dels voltatges són els típics.
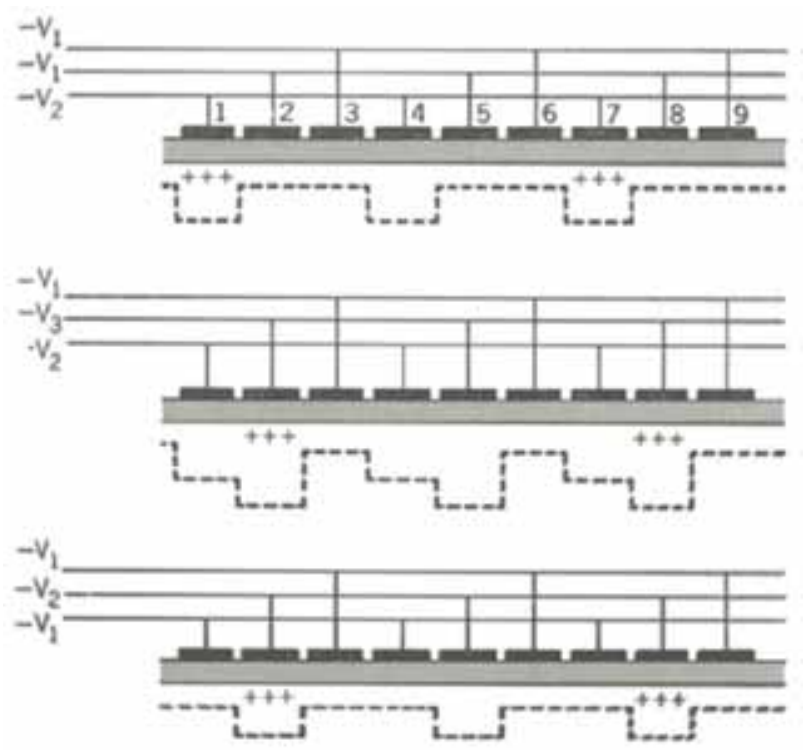

Figura 17. Les tres fases mitjançant les quals és possible traslladar les càrregues d'un sensor al següent, aplicant un cicle convenient de voltatges. 


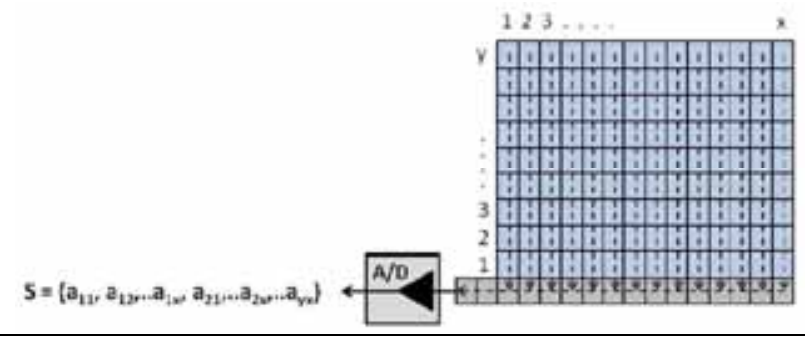

Figura 18. Lectura de dades de la matriu de sensors i posterior conversió analògic-digital.

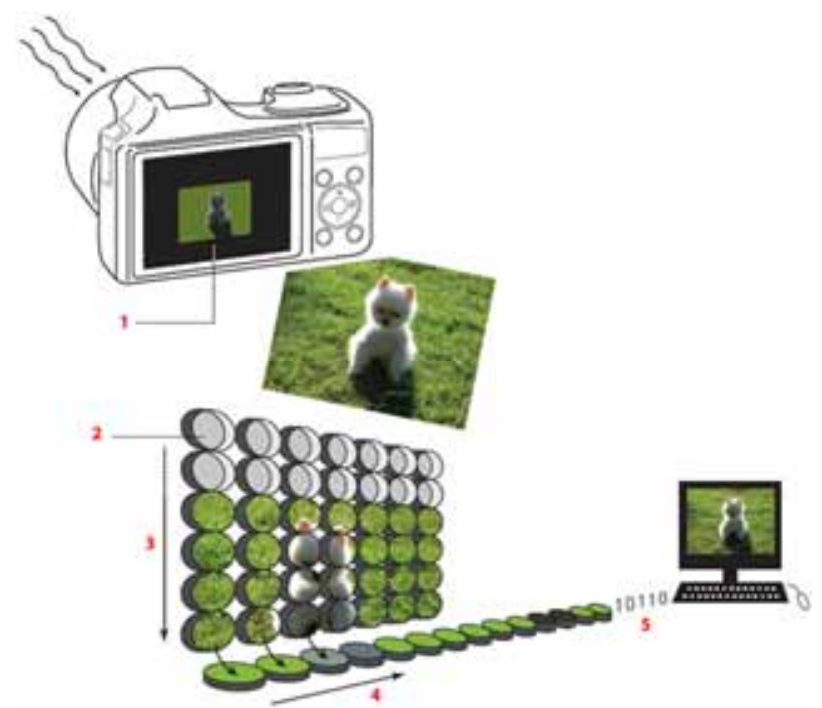

Figura 19. II·lustració del procés d'obtenció i digitalització de la imatge en un sensor CCD. La imatge lluminosa es projecta sobre el sensor (1) on cada cel-la sensible (2) recull els valors corresponents d'intensitat. Aquests valors són transferits ordenadament d'una filera a la següent (3) per obtenir una sèrie de valors (4) que finalment són digitalitzats (5) per poder ser descodificats i reconstruir la imatge.

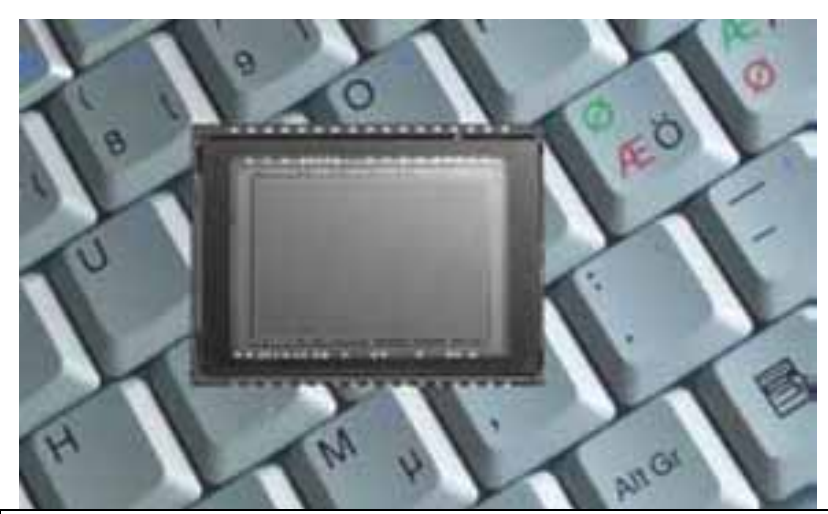

Figura 20. Mida d'un sensor CCD per comparació amb un teclat.
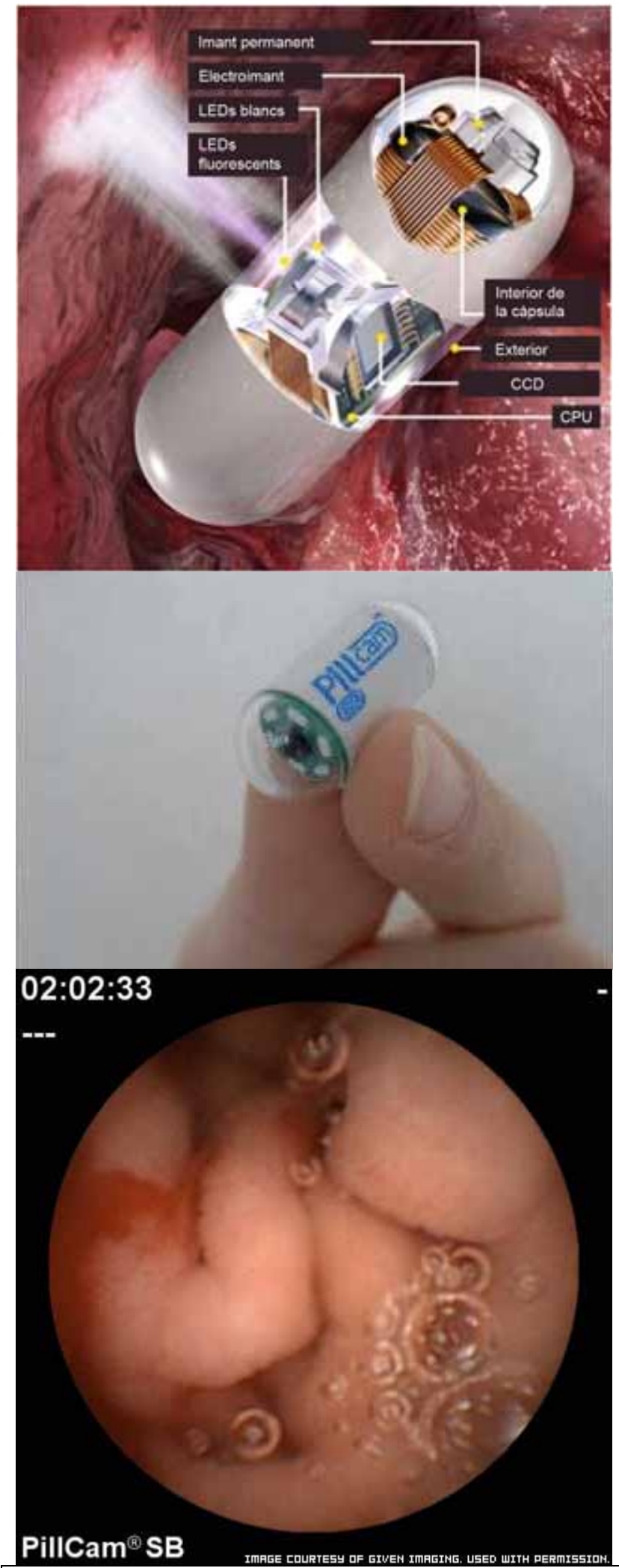

Figura 21. Endoscòpia amb càpsula. De dalt a baix: estructura de la càpsula, aspecte extern i imatge obtinguda. (link.brightcove.com) 
Els sensors CCD (fig. 20) són més sensibles que les pel-lícules fotogràfiques, amb l'avantatge addicional de proporcionar la imatge en format digital, amb totes les possibilitat de tractament que això suposa. Per tot plegat han trobat utilitat en camps molt diversos: càmeres digitals, escàners, fotocopiadores, lectors de codi de barres, dispositius mèdics d'exploració (fig. 21), teledetecció, astronomia... El telescopi espacial Hubble, per exemple, obté les seves imatges mitjançant sensors CCD.

\section{La transmissió d'informació}

No es podria entendre l'actual xarxa d'Internet sense dispositius que permetin la transmissió eficaç a molta distància de grans quantitats d'informació. Tot i que s'utilitzen ones de ràdio i transmissió per cable conductor, ha estat decisiva l'aparició de la fibra òptica, que permet una transmissió de dades de gran capacitat.

Per transmetre informació mitjançant ones cal modular-la, ja sigui en amplitud (fig. 22) o en freqüència.

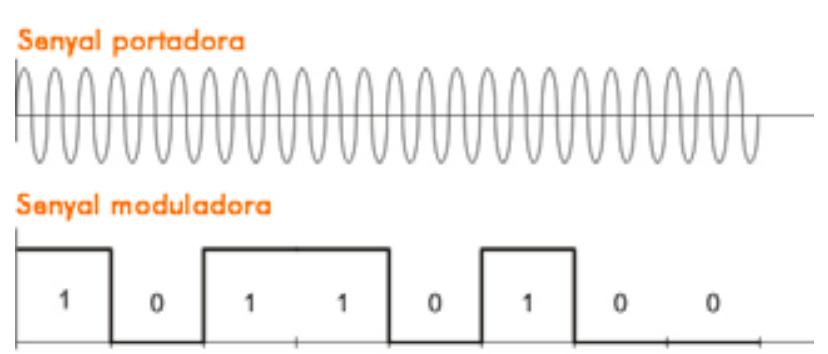

Senyal modulada

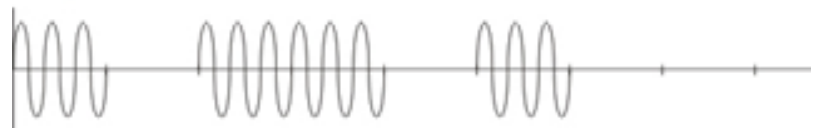

Figura 22. L'ona portadora, el senyal a transmetre, i el senyal modulat en amplitud.

Encara que la portadora tingui una freqüència precisa, al transportar informació la freqüència utilitzada esdevé un interval (fig. 23): l'anomenat ample de banda. (No s'ha de confondre amb el mateix terme, utilitzat en tecnologia digital, on s'anomena així als bits que un canal és capaç de transmetre cada segon). L'atenuació d'un senyal que comença amb una potència $P_{1}$ i l'acaba amb $P_{2}$ es defineix com $10 \log _{10} P_{1} / P_{2}$. Una atenuació de $3 \mathrm{~dB}$ equival aproximadament a dividir la potència per 2 .

La transmissió d'informació modulant llum ja la va utilitzar el 1880 Alexander Graham Bell al construir un fotòfon (fig. 24), que transportava informació sonora mitjançant ones lluminoses. Es tractava d'un precedent de l'actual tecnologia de transmissió d'informació mitjançant la llum, només que l'actual es basa en la fibra òptica (fig. 25): una tecnologia que deu molt als treballs de Charles Kao, que li han valgut el premi Nobel del 2009.

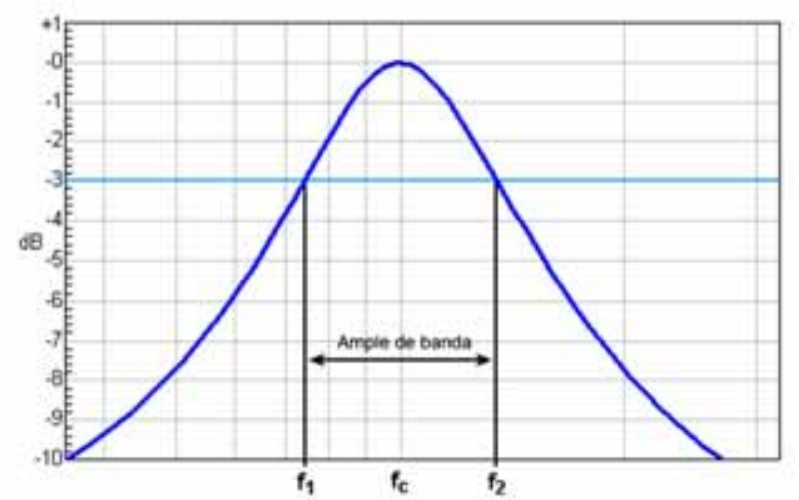

Figura 23. Un senyal modulat es considera que ocupa un interval de freqüències (ample de banda) entorn de la freqüència central, $f_{c}$, interval on l'atenuació del senyal no supera els $3 \mathrm{~dB}$.
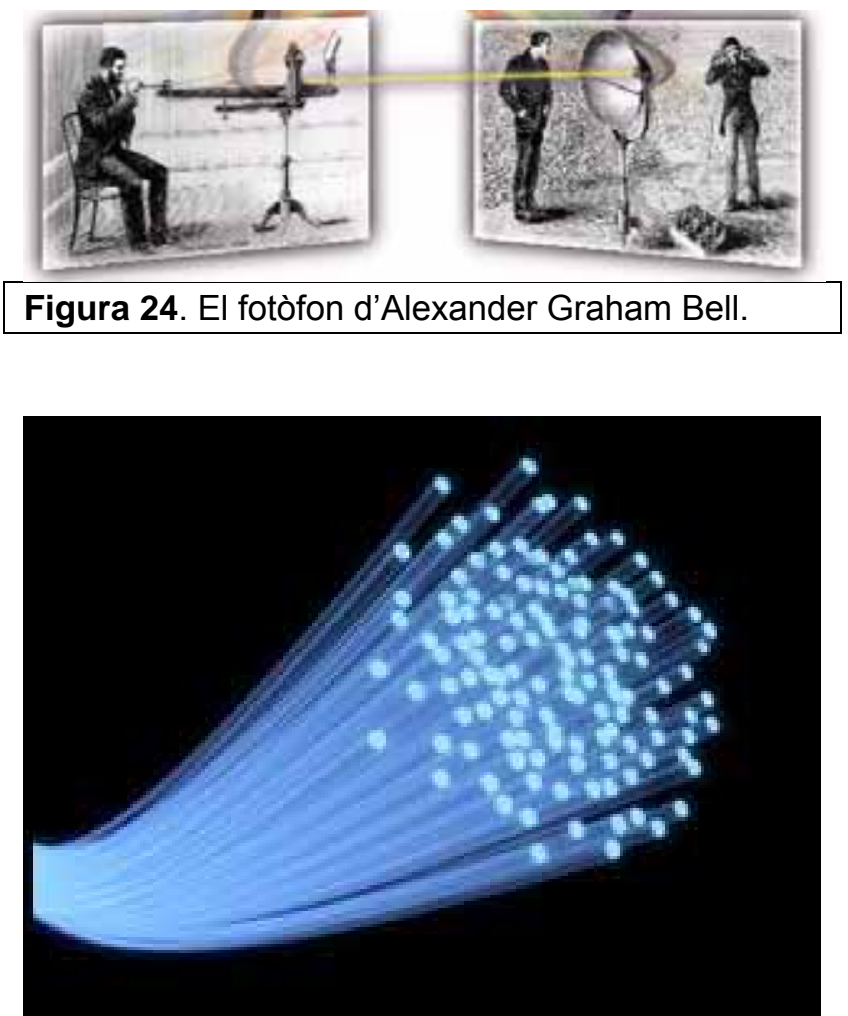

Figura 25. Feix de fibres òptiques.

\section{La fibra òptica}

La fibra òptica es basa en la refracció total de la llum en un medi de propagació. Segons la llei de la 
refracció, quan un feix lluminós es propaga d'un medi 1 a un altre, 2, l'angle que forma amb la normal a la superfície de separació en cada medi compleix la relació

$$
\mathrm{n}_{2} \operatorname{sen} \theta_{2}=\mathrm{n}_{1} \operatorname{sen} \theta_{1}
$$

on cadascuna de les $n$ són l'índex de refracció de la llum al medi respectiu, és a dir, el quocient entre la velocitat de la llum en el buit i en aquell medi:

$$
\mathrm{n}_{1}=\mathrm{c} / \mathrm{v}_{1} \quad \mathrm{n}_{2}=\mathrm{c} / \mathrm{v}_{2}
$$

D'aquesta manera, tant l'angle d'incidència com els índex de refracció determinen l'angle de refracció (fig. 26).

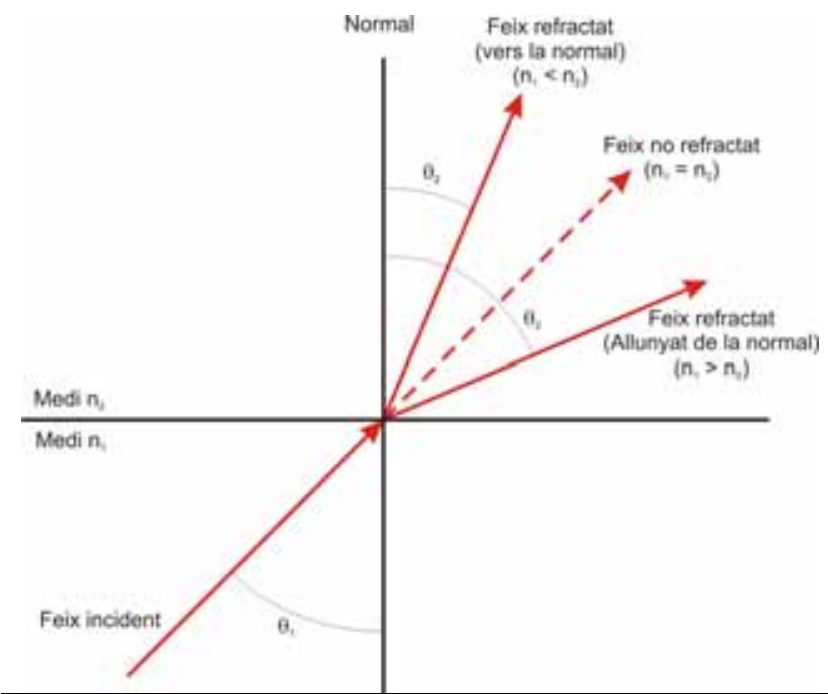

Figura 26. L'angle de refracció depèn de la relació entre els índexs de refracció.

Però quan l'índex de refracció del primer medi és superior a la del segon, augmentant l'angle d'incidència arriba un moment que ja no es produeix refracció, sinó una reflexió i el feix lluminós resta al mateix medi d'origen: és la refracció total (figs. 27 i 28).

És fàcil calcular que en el cas de l'aire $(n=1) i$ el vidre $(n=1,5)$, quan la llum ha de passar del vidre a l'aire, l'angle límit seria el corresponent a $\theta_{2}=$ $90^{\circ} \mathrm{i}$, per tant,

$$
\begin{gathered}
1,5 \operatorname{sen} \theta_{1}=1 \\
\theta_{1}=41.8^{\circ}
\end{gathered}
$$

Això vol dir que sempre que l'angle d'incidència la llum respecte de la normal sigui superior a $41,8^{\circ}$ es produirà reflexió total i la llum quedarà dins del medi vidre.

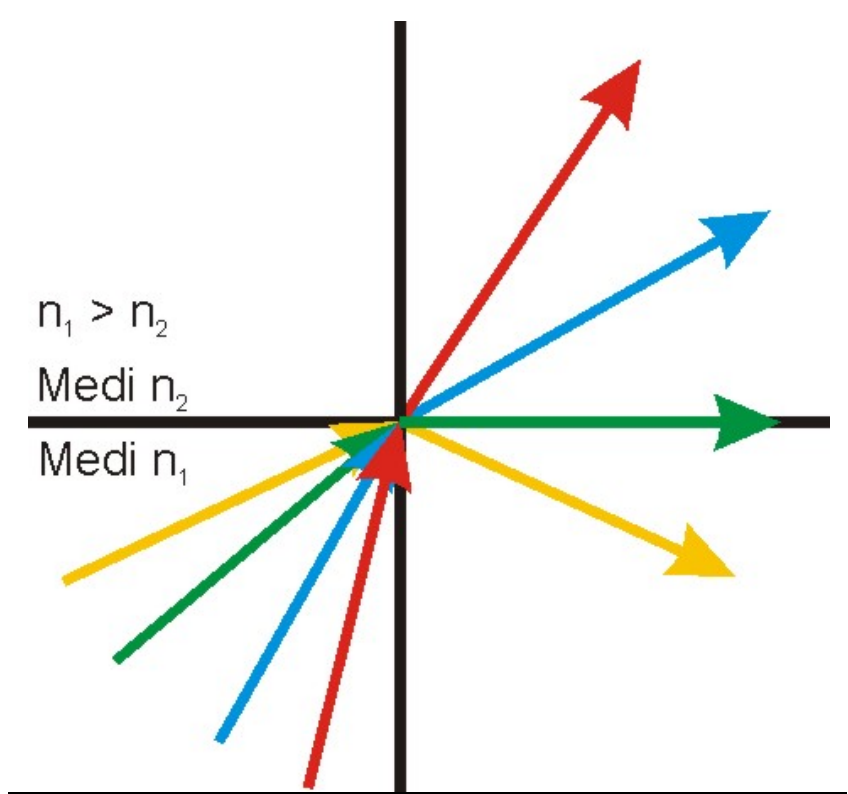

Figura 27. Quan $n_{1}>n_{2}$, al superar un determinat angle d'incidència (verd) es produeix refracció total.

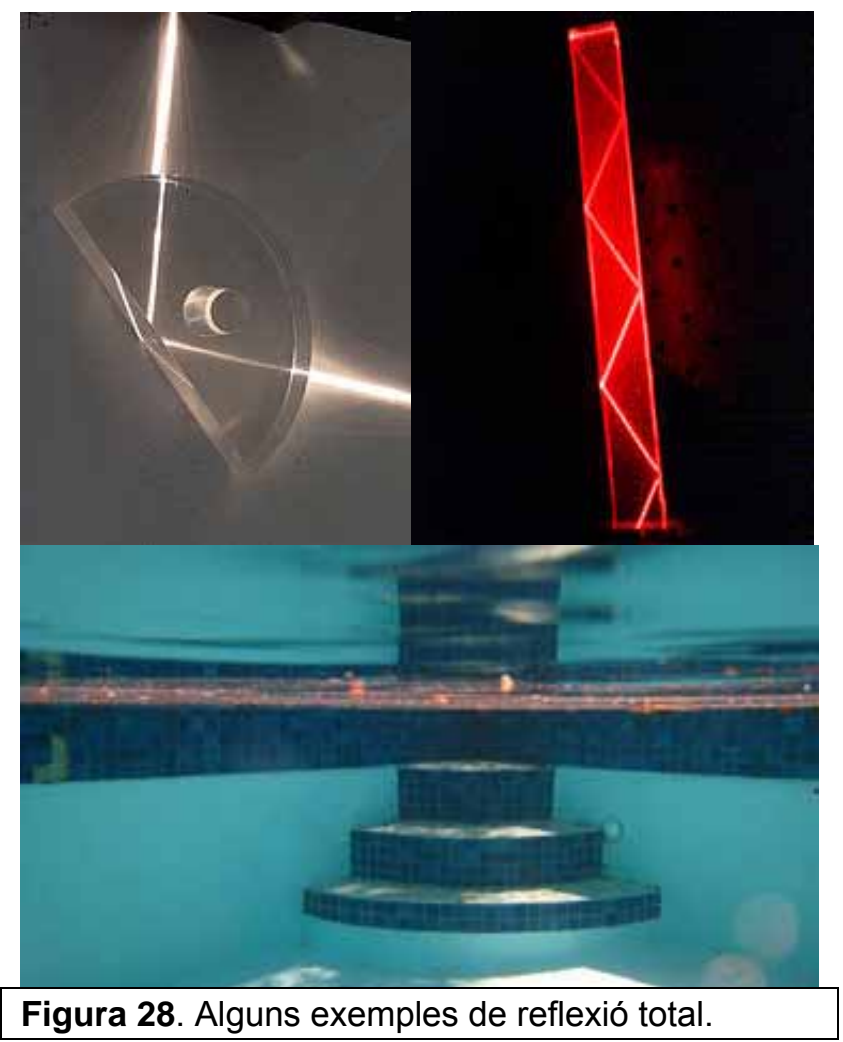

A més a més, diversos senyals s'hi poden propagar independentment sense perdre qualitat (fig. 29). Però la transmissió de senyals per fibra òptica ha hagut de superar diversos problemes. 


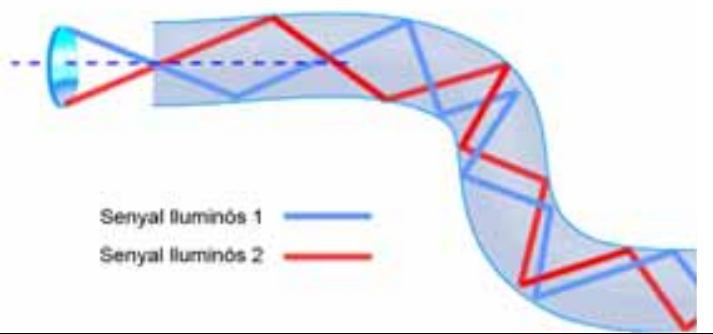

Figura 29. Diversos senyals poden propagar-se pel mateix medi.

Per exemple, per evitar que un feix de llum pugui passar a les fibres del costat es va cobrir cada fibra d'un revestiment amb un índex de refracció superior al del nucli (fig. 30). Una forma d'evitar aquest comportament va ser reduir l'amplada del nucli (fig. 31).

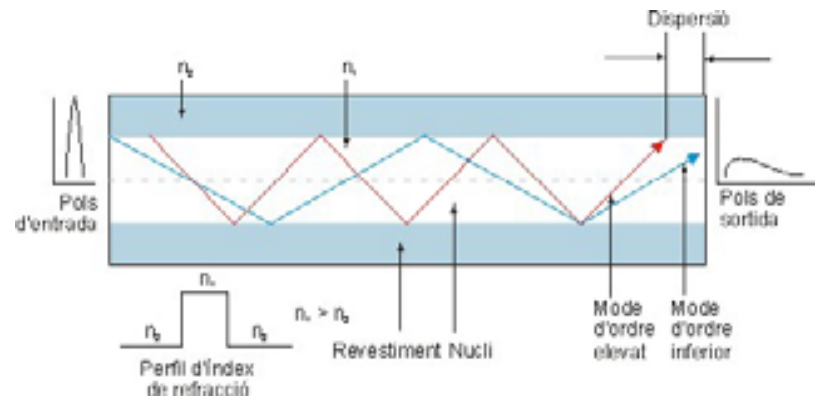

Figura 30. La diferent inclinació dels raigs acaba produint una dispersió en el senyal, és a dir, una pèrdua de qualitat.

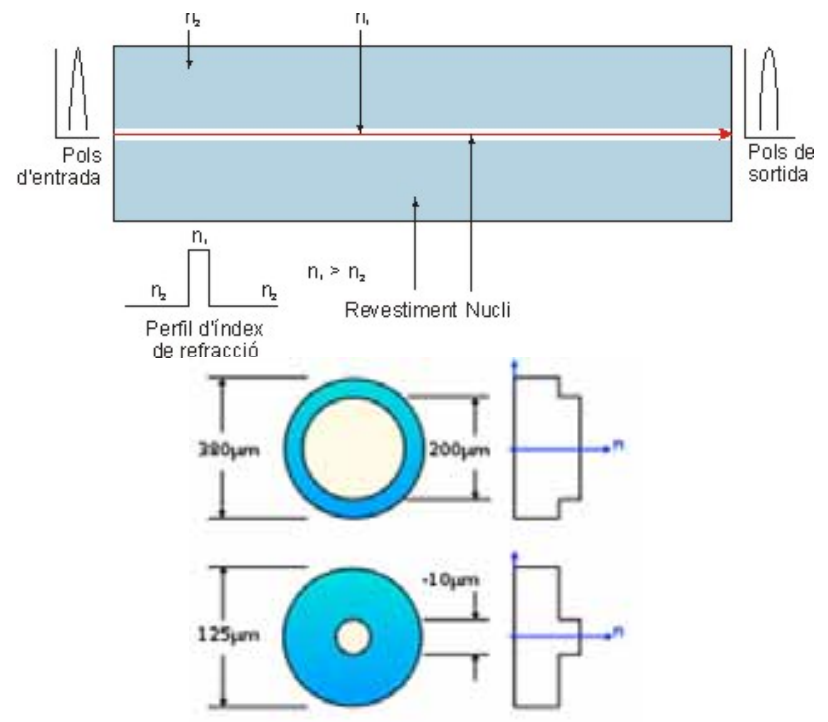

Figura 31. Reduint l'amplada del nucli es disminueix la dispersió del senyal. A sota, valors típics dels diàmetres de les fibres òptiques.
Altres factors que augmenten l'atenuació del senyal en fibres òptiques són:

- Pèrdues per absorció del material de la fibra, degudes a impureses com ions metàl-lics, radicals hidroxil $\left(\mathrm{OH}^{-}\right)$, etc. que absorbeixen llum i la converteixen en calor. El vidre ultrapur utilitzat per fabricar fibres òptiques té una puresa aproximada del 99,9999\%.

- Les pèrdues per dispersions de diversos tipus, com la de Rayleigh, responsable del $96 \%$ de l'atenuació, imperfeccions en la unió nucli-revestiment, petites variacions geomètriques, minúscules bombolles en el nucli...

Com es pot veure a la fig. 32, al llarg dels darrers decennis la ciència ha estat capaç d'anar reduint aquestes pèrdues, fent que la fibra òptica sigui ja una tecnologia madura. En aquest èxit hi van tenir una paper important els treballs de Charles Kao realitzats a principis dels anys 60 .

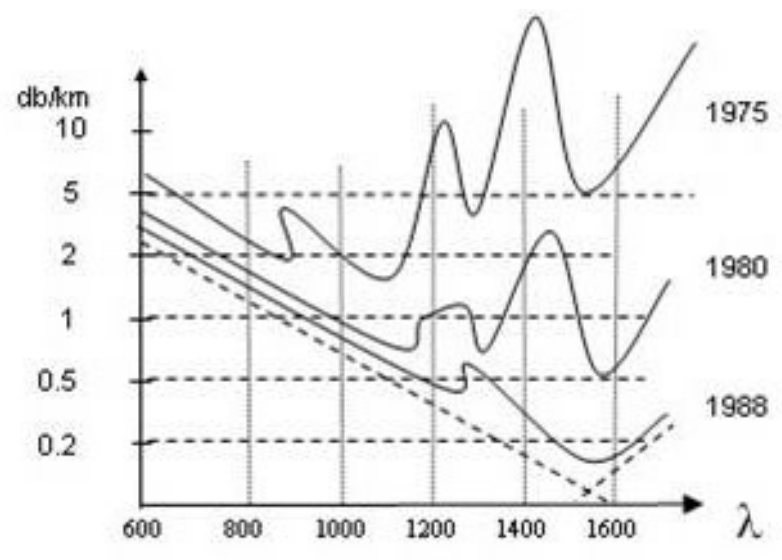

Figura 32. Variació al llarg dels anys de l'atenuació del senyal per quilòmetre en fibres òtiques segons la longitud d'ona.

Actualment, quan es tracta de moure grans fluxos d'informació, com en els cables submarins (fig. 33), la fibra òptica ha desplaçat completament el cable elèctric, gràcies a la seva gran capacitat (taula 1).

Per a la transmissió d'informació, els avantatges de la fibra òptica en relació als conductors de coure són els següents:

- Preu més barat

- Actualment les fibres ja són més primes que els conductors, permetent posar-ne més en el mateix espai

- Menor degradació del senyal durant la seva propagació 
- Els diversos senyals que es transmeten per una fibra no interfereixen entre si, mantenint la seva qualitat

- Baix consum, ja que al no degradar-se tant requereixen menys energia per amplificar-les pel camí

- Millors per al transport de senyals digitals, gràcies a l'elevada freqüència de la llum i a la seva capacitat de modulació

- Sense risc d'inflamació al no passar-hi corrent elèctric

- Menor pes

\begin{tabular}{|l|l|l|}
\hline En servei & Tipus & Canals \\
\hline $1956-1978$ & Cable elèctric & 48 \\
\hline $1959-1982$ & Cable elèctric & 72 \\
\hline $1963-1986$ & Cable elèctric & 276 \\
\hline $1965-1987$ & Cable elèctric & 345 \\
\hline $1970-1993$ & Cable elèctric & 2112 \\
\hline $1976-1994$ & Cable elèctric & 10000 \\
\hline $1978-1994$ & Cable elèctric & 10500 \\
\hline \multicolumn{3}{|l}{} \\
\hline $1988-2002$ & Fibra òptica & 40000 \\
\hline $1992-2004$ & Fibra òptica & 80000 \\
\hline $1992-2003$ & Fibra òptica & $2 \times 565 \mathrm{Mbit} / \mathrm{s}$ \\
\hline $1993-2003$ & Fibra òptica & $2 \times 565 \mathrm{Mbit} / \mathrm{s}$ \\
\hline $1996-2008$ & Fibra òptica & $12 \times 2,5 \mathrm{Gbit} / \mathrm{s}$ \\
\hline $2000-$ & Fibra òptica & $64 \times 10 \mathrm{Gbit} / \mathrm{s}$ \\
\hline
\end{tabular}

Taula 1. Dades dels cables submarins transatlàntics. El canvi de tecnologia ha permès un salt important en la seva capacitat.

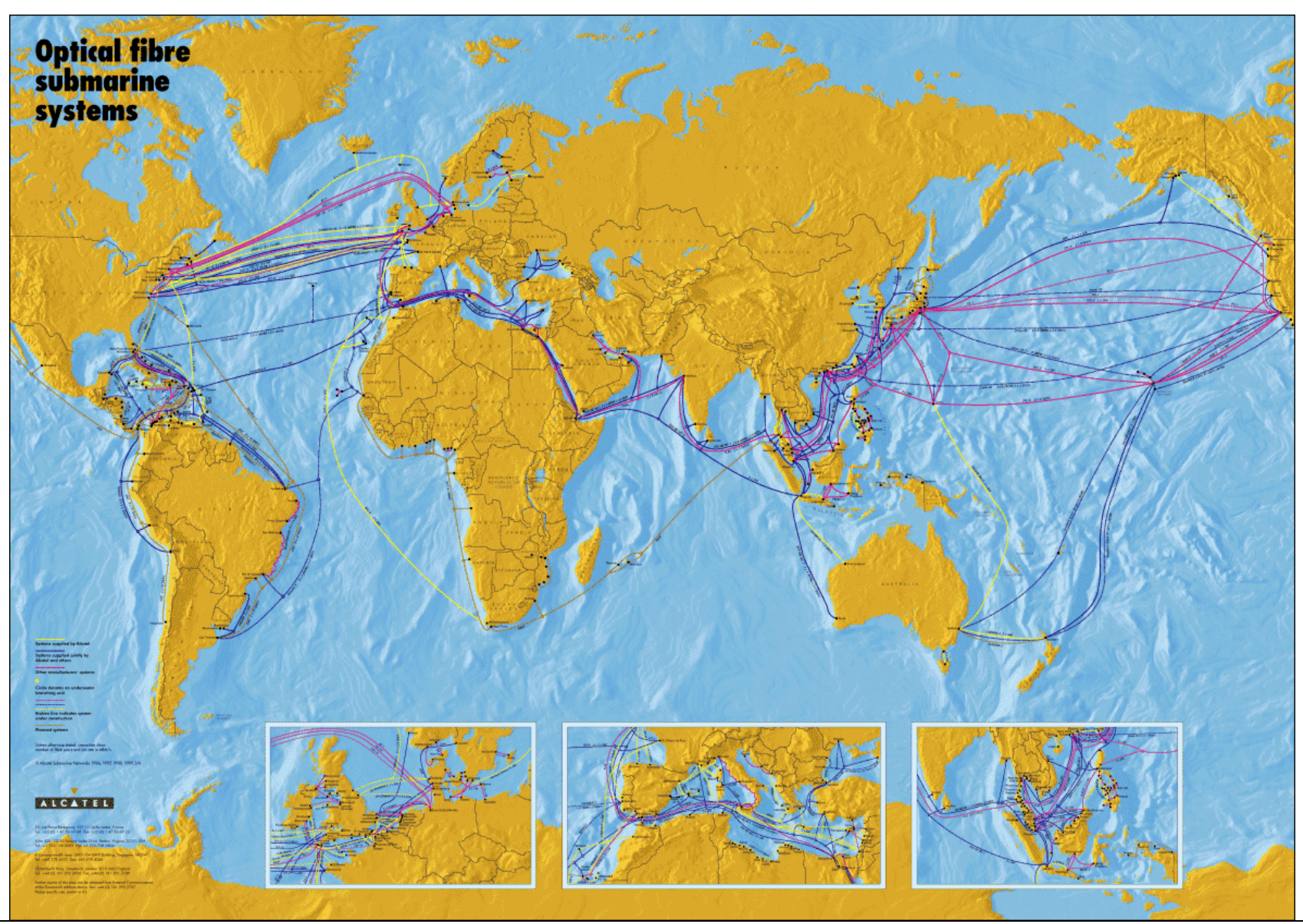

Figura 33. Sistema mundial de fibres òptiques submarines, 2005. (alcatel) 